\title{
Association between the food retail environment surrounding schools and overweight in Canadian youth
}

\author{
Laura M Seliske', William Pickett ${ }^{1,2}$, William F Boyce ${ }^{1,3}$ and lan Janssen ${ }^{1,4, *}$ \\ ${ }^{1}$ Department of Community Health and Epidemiology, Queen's University, Kingston, Ontario, Canada: \\ ${ }^{2}$ Department of Emergency Medicine, Queen's University, Kingston, Ontario, Canada: ${ }^{3}$ Social Program \\ Evaluation Group, Faculty of Education, Queen's University, Kingston, Ontario, Canada: ${ }^{4}$ School of Kinesiology \\ and Health Studies, Queen's University, Kingston, Ontario, Canada, K7L 3N6
}

Submitted 29 February 2008: Accepted 29 September 2008: First published online 17 December 2008

\begin{abstract}
Introduction: There is growing interest in how the physical environment influences obesity. Few studies have considered how the food retail environment surrounding schools influences overweight in students.

Objective: To determine whether there is a relationship between food retailers surrounding schools and overweight among Canadian youth.

Design: Cross-sectional study.

Setting/methods/subjects: The number of food retailers was obtained within a $1 \mathrm{~km}$ and $5 \mathrm{~km}$ radius around 178 schools in Canada. Retailers included fullservice restaurants, fast-food restaurants, sub/sandwich retailers, doughnut/coffee shops, convenience stores and grocery stores. An index of total food retailer exposure was also created. Multilevel analyses were used to control for individual- and area-level covariates.

Results: None of the individual food retailers was associated with an increased likelihood of overweight. The total food retailer index was most strongly related to overweight, but in the opposite direction to that hypothesized. At $1 \mathrm{~km}$, students attending schools with at least one food retailer had a lower relative odds of overweight (OR $=0 \cdot 70,95 \% \mathrm{CI} 0 \cdot 61,0 \cdot 81)$. At $5 \mathrm{~km}$, students attending schools with the highest exposure to the total food retailer index had a lower relative odds of overweight (OR $=0 \cdot 56,95 \% \mathrm{CI} 0 \cdot 47,0 \cdot 68)$ compared with students attending schools with no exposure.

Conclusions: Exposure to various types of food retailers in school neighbourhoods was not associated with an increased likelihood of overweight in Canadian school-aged youth. The opportunity to make healthy choices from a variety of options and the unique Canadian context may explain the findings.
\end{abstract}

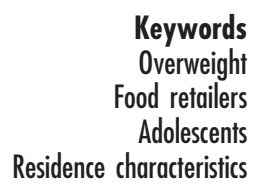

Childhood obesity is a significant public health problem. Among Canadian youth, one child in four is overweight or obese ${ }^{(1)}$. Unfortunately, weight-loss interventions in obese children and youth have been largely ineffective ${ }^{(2)}$. Thus, efforts to combat the childhood obesity epidemic will likely need to focus on obesity prevention rather than obesity treatment. It is essential to fully understand the factors that contribute to childhood obesity to create optimal obesity prevention strategies and policies.

Existing research on the aetiology of obesity has focused on obesity-promoting (obesogenic) behaviours and has largely ignored the environmental factors that may dictate or mediate these behaviours ${ }^{(3)}$. One aspect of the environment that may influence obesogenic behaviours is access to food retailers. To illustrate, some neighbourhoods may have a preponderance of food retailers and restaurants selling unhealthy, energy-dense foods that promote obesity. A state-level analysis conducted in the USA found that the density of neighbourhood fast-food retailers was positively associated with obesity ${ }^{(4)}$. A large cohort study of adults reported that a greater number of neighbourhood supermarkets was associated with a lower likelihood of obesity, while a greater number of convenience stores was associated with a higher likelihood of obesity ${ }^{(5)}$. These findings highlight the potential relevance of the food retail environment.

To our knowledge, only two studies have examined the relationship between the food retailer environment and adiposity in children and youth. Burdette and Whitaker ${ }^{(6)}$ did not find a relationship between the proximity to fastfood restaurants and overweight in pre-school children living in a low-income neighbourhood in Cincinnati, Ohio. Similarly, a longitudinal study of kindergarten students across the USA found that the number of fast-food 
restaurants, full-service restaurants and convenience stores in the neighbourhood was not related to obesity in the third $\operatorname{grade}^{(7)}$. It is noteworthy that these studies were conducted in young children who do not have the same degree of dietary autonomy as older children. Furthermore, results from these American studies may not be transferable to other countries or populations. Finally, because students spend a considerable portion of their day at school and because food retailers cluster around schools ${ }^{(8)}$, the food environment surrounding schools may be an important determinant of obesogenic behaviours in youth.

The aim of the present study was to determine whether a relationship exists between the food retailer environment and rates of overweight and obesity in Canadian youth. Specifically, the study considered whether the number of different types of food retailers in the environment surrounding schools and the broader neighbourhood in which youth live is related to obesity rates. It was hypothesized that the number of neighbourhood food retailers that sell primarily energy-dense foods (fast-food restaurants, convenience stores and coffee/doughnut shops) would be positively associated with overweight and obesity, while the number of retailers that tend to offer healthier food choices (such as sub/sandwich shops, full-service restaurants, grocery stores) would be negatively associated with overweight and obesity.

\section{Experimental methods}

\section{Survey}

The study sample involved Canadian students participating in the 2005/06 Health Behaviour in School-aged Children (HBSC) survey ${ }^{(9)}$. The HBSC is a cross-national survey performed in collaboration with the WHO. The sampling approach used the school class as the unit of selection, with classroom grades chosen to reflect the distribution of students in grades 6-10 in the Canadian population. Schools were selected using a weighted probability technique to ensure that the sample was representative by regional geography and key demographic features (religion, community size, school size, language of instruction). Schools from each province and territory, as well as urban and rural locations, were represented. Youth attending private or special needs schools, incarcerated youth and youth not enrolled in school were excluded. Combined, these excluded individuals represent $\sim 9 \%$ of the study age group in Canada ${ }^{(10)}$. A total of 9672 students from 188 schools participated in the 2005/06 survey. Of the students selected for the study, $74 \cdot 2 \% \mathrm{com}-$ pleted the questionnaire, and their demographic profile was representative of Canadians in the same age range. Ethics approval was obtained from the Queen's University General Research Ethics Board. Consent was obtained at the school board and school levels, as well as from students and their parents.

\section{Measurement of neighbourbood food retailers}

\section{Classification of food retailer types}

Information was obtained on the location and type of food retailers surrounding schools using the street addresses of the participating schools. This was obtained through an Internet-based food retailer database (www.yellow.ca). To ensure that each food retailer was classified into mutually exclusive categories, a classification strategy was created whereby chain retailers were assigned to one of the categories of food retailers. Information was initially collected on twelve types of food retailers, which were then collapsed to obtain the six categories of food retailers used in the analysis. Large chain retailers were categorized into the six groups first, and the remaining independent retailers were subsequently categorized. A variable measuring the total number of food retailers was also obtained by summing the individual food retailers.

\section{Distance of food retailers from schools}

The number and type of food retailers within a $1 \mathrm{~km}$ distance was chosen to represent food sources students would have close access to. This distance was chosen because it corresponds to an approximate 10-15 min oneway walk ${ }^{(8,11)}$. It was expected that students were able to access these retailers on their way to and from school and during breaks in the school day. In addition to exposure to food retailers within close proximity to schools, information was also collected on food retailers within the broader school neighbourhood. The number and type of food retailers within a $5 \mathrm{~km}$ radius was chosen to represent food sources that students and their families would have close access to in their neighbourhoods. A sensitivity analysis from a previous HBSC study in Canada showed no differences in area-level socio-economic status (SES) between the $1 \mathrm{~km}$ and $5 \mathrm{~km}$ distance ${ }^{(12)}$. Therefore, the $5 \mathrm{~km}$ distance was chosen because it would be more inclusive of residences of students attending the schools.

\section{Classification of food retailer exposure groups}

For the $1 \mathrm{~km}$ radius, schools were categorized into two groups for each food retailer type: those with no exposure to food retailers and those with exposure to one or more retailer. At this distance we felt it was not the number of food retailers that is important per se, but rather whether students had access to that type of food retailer. For each food retailer type, exposure was determined by whether there was a given type of food retailer within a $1 \mathrm{~km}$ radius. For example, a school was considered exposed to full-service restaurants if there was at least one full-service restaurant within the $1 \mathrm{~km}$ radius. This was repeated for fast-food restaurants, sub/sandwich shops, doughnut/coffee shops and convenience stores. Similarly, a total food retailer index was created, whereby schools were divided into two groups indicating whether they were exposed or not exposed to any food retailers. 
Food retailers within a $5 \mathrm{~km}$ radius of the schools were classified into four groups: the first group had no retailers and the remainder was divided into tertiles, herein referred to as low, medium and high exposure categories. This was done for all six types of food retailers. A total food retailer index was also created, whereby a category was created for schools with no exposure to any food retailers and the remaining schools with exposure to at least one food retailer were divided into tertiles, indicating low, medium and high exposure.

For the $5 \mathrm{~km}$ distance, a population food retailer density was also calculated by dividing the number of each type of retailer by the number of people living within the $5 \mathrm{~km}$ radius. The number of people living within $5 \mathrm{~km}$ of schools was obtained from PCensus (2001 Census of Canada Profile Data, version 2001; Tetrad Computer Applications Inc., Bellingham, WA, USA) based upon the schools' civic addresses. The number of food retailers was divided by the population within $5 \mathrm{~km}$ and was multiplied to obtain the number of retailers per 10000 people. The density measure took into consideration the size of the population sharing access to the various food retailers, as performed in a number of similar studies ${ }^{(7,13-15)}$.

\section{Measurement of neighbourbood-level covariates}

Area-level SES and urban-rural status could potentially explain differences in the availability of food retailers. Previous studies have shown a consistent relationship between area-level SES and adiposity status in Canadian youth $^{(16-18)}$. Using methods developed by Oliver and Hayes $^{(16)}$, the area-level SES was obtained for individuals living within $5 \mathrm{~km}$ of schools using PCensus for the 2001 Canadian Census. Values for median household income, unemployment rate and percentage of the population with less than a high school education were ranked for each of the schools and the sum of the rankings was obtained. This summed value was used to dichotomize the school neighbourhoods as high or low SES. Much of the existing research on the relationship between food retailers and overweight has taken place in largely urban areas. However, schools that participated in the HBSC varied in their geographical status. Urban-rural status of the participating schools was obtained through a postal code analyser using Statistics Canada data. Schools located in areas that had a population greater than 10000 people were considered urban, while those with a smaller population were not considered urban, which was consistent with the definition used by Statistics Canada ${ }^{(19)}$.

\section{Measurement of individual-level variables}

\section{Overweight and obesity (outcome)}

Students self-reported their height and weight on the HBSC survey, and this information was used to calculate their BMI $\left(\mathrm{kg} / \mathrm{m}^{2}\right)$. Overweight and obesity were defined using the age- and sex-specific BMI cut-off points recommended by the International Obesity Taskforce ${ }^{(20)}$. Youth whose BMI corresponded to the adult value of $\geq 25 \mathrm{~kg} / \mathrm{m}^{2}$ were classified as overweight (including both overweight and obese), while those whose BMI corresponded to the adult value of $\geq 30 \mathrm{~kg} / \mathrm{m}^{2}$ were classified as obese.

\section{Covariates}

Individual-level confounders included age and sex. Because physical activity is associated with lower levels of obesity ${ }^{(21)}$, it was also considered as a potential confounder. Students were asked how many days per typical week they were physically active for at least $60 \mathrm{~min}$, with options ranging from 0 to $7 \mathrm{~d}$. The Family Affluence Scale, a measure of family wealth developed for use in the $\mathrm{HBSC}^{(22)}$, was also included as a covariate. This scale is based on four questions regarding car ownership, bedroom sharing, holiday travel and computer ownership. Individual-level SES was considered a potential confounder because of its association with obesity ${ }^{(16,23)}$ and access to food retailers ${ }^{(14,24-26)}$.

\section{Statistical analysis}

Spearman's correlations were calculated to examine the relationship between the number of individual food retailers and the total food retailer index for the neighbourhoods of the participating schools. Regression analyses were performed to examine the association between food retailers and overweight. Multilevel modelling regression procedures were used to take into account the clustered nature of the data and to allow for simultaneous consideration of both individual-level and area-level variables as predictors of the overweight outcome ${ }^{(27)}$. The Hierarchical Linear Modeling (HLM) software package version 5.05 (Scientific Software International, Lincolnwood, IL, USA) was used to perform multilevel logistic regression. Overweight (including both overweight and obese youth) was the binary outcome considered in the logistic models.

A three-step modelling process was used. Initially, each covariate was examined bivariately with the outcome variables. At this stage, the individual-level variables were assessed to determine whether there were complex level2 effects, whereby the relationship between individuallevel variables and overweight differed across schools. No complex level-2 effects were found and the effects of individual level variables were treated as fixed across all schools. Thus, all models in the analysis were random intercept models. The second phase of the modelling process involved the creation of multivariate models. Covariates that were significantly related to the outcome variable $(P<0.05)$ in the bivariate analysis were considered in the multivariate models, which were created using a manual stepwise approach.

For the $1 \mathrm{~km}$ analysis, the variables were added in order starting with the lowest $P$ value. In the $5 \mathrm{~km}$ analysis the average $P$ value from the various exposure groups was used to determine the order in which the food retailers were entered into the model. The third phase of the modelling process involved the total food retailer 
index variable to determine if the combined effect of the food retailers was more strongly predictive of overweight and obesity than each retailer individually. Due to problems in converging multilevel models with several area-level variables included, the food retailers were not included, forced or retained in the stepwise multivariate models unless they were statistically significant.

\section{Results}

\section{Descriptive characteristics}

A total of 9672 students from 188 schools participated in the 2005/05 HBSC survey, but due to incomplete information, the analysis was limited to $7281(75 \cdot 2 \%)$ students from 178 schools. A mean of forty-two students per school participated in the survey, with a range of one to 176 students per school. The average prevalence of overweight and obesity in students was $22 \cdot 2 \%$ across schools, and ranged from 0 to $53 \cdot 8 \%$. The number of overweight and obese students is presented in Table 1. Of the individuallevel variables listed in Table 1 , only age was not significantly $(P<0 \cdot 05)$ associated with overweight and obesity. Thus, all of the individual-level variables, with the exception of age, were included as covariates in the multivariate regression models. Descriptive details on the area-level variables are shown in Table 2. Of the area-level covariates, urban-rural status but not area-level SES was related to overweight; therefore, urban-rural status was

Table 1 Individual-level demographic characteristics of the study participants: Canadian students participating in the 2005/06 Health Behaviour in School-aged Children Survey

\begin{tabular}{lrrr}
\hline & $n$ & $\%$ & $\mathrm{SE}$ \\
\hline Sex & & & \\
$\quad$ Males & 3878 & $48 \cdot 6$ & $0 \cdot 6$ \\
Females & 4109 & $51 \cdot 5$ & $0 \cdot 6$ \\
Age (years) & & & \\
$\leq 11$ & 777 & $9 \cdot 7$ & $0 \cdot 3$ \\
12 & 1204 & $15 \cdot 1$ & $0 \cdot 4$ \\
13 & 1491 & $18 \cdot 7$ & $0 \cdot 4$ \\
14 & 1897 & $23 \cdot 8$ & $0 \cdot 5$ \\
15 & 1894 & $23 \cdot 7$ & $0 \cdot 5$ \\
$\geq 16$ & 724 & $9 \cdot 1$ & $0 \cdot 3$ \\
BMI (kg/m ${ }^{2}$ ) & & & \\
Normal weight & 6251 & $78 \cdot 3$ & $0 \cdot 5$ \\
Overweight & 1278 & $16 \cdot 0$ & $0 \cdot 4$ \\
Obese & 458 & $5 \cdot 7$ & $0 \cdot 3$ \\
Physical activity (d/week active for $\geq 60$ min) & & & \\
0 & 156 & $2 \cdot 0$ & $0 \cdot 2$ \\
1 & 396 & $5 \cdot 0$ & $0 \cdot 2$ \\
2 & 743 & $9 \cdot 4$ & $0 \cdot 3$ \\
3 & 1099 & $13 \cdot 9$ & $0 \cdot 4$ \\
4 & 1168 & $14 \cdot 7$ & $0 \cdot 4$ \\
5 & 1576 & $19 \cdot 9$ & $0 \cdot 4$ \\
6 & 1258 & $15 \cdot 9$ & $0 \cdot 4$ \\
7 & 1539 & $19 \cdot 4$ & $0 \cdot 4$ \\
Family Affluence Scale & & & \\
1 (least affluent) & 905 & $11 \cdot 3$ & $0 \cdot 4$ \\
2 & 2991 & $37 \cdot 5$ & $0 \cdot 5$ \\
3 (most affluent) & 4091 & $51 \cdot 2$ & $0 \cdot 6$ \\
\hline
\end{tabular}

also included as a covariate in the multivariate regression models.

\section{Relationship between neighbourbood food retailers}

Correlations among the various food retailers was assessed and ranged from 0.41 to 0.73 for food retailers within the $1 \mathrm{~km}$ radius and 0.79 to 0.93 for food retailers within the $5 \mathrm{~km}$ radius (data not shown). In general, the number of full-service restaurants was the most highly correlated with the total food retailer index, while the number of convenience stores and fast-food restaurants were the least correlated with the other food retailer types and the total food retailer index.

\section{Relationship between food retailers and overweight}

$1 \mathrm{~km}$ Distance

As indicated in Table 2, full-service restaurants were the most common food retailer located within $1 \mathrm{~km}$ of schools, with over two-thirds of schools having at least

Table 2 Area-level demographic characteristics of the study participants: Canadian schools participating in the 2005/06 Health Behaviour in School-aged Children Survey

\begin{tabular}{|c|c|c|c|c|}
\hline & \multicolumn{2}{|c|}{$n$} & $\%$ & SE \\
\hline \multicolumn{5}{|l|}{ Province } \\
\hline Alberta & \multicolumn{2}{|c|}{23} & $12 \cdot 2$ & $2 \cdot 4$ \\
\hline British Columbia & \multicolumn{2}{|c|}{17} & $9 \cdot 0$ & $2 \cdot 1$ \\
\hline Manitoba & \multicolumn{2}{|c|}{7} & $3 \cdot 7$ & $1 \cdot 4$ \\
\hline New Brunswick & \multicolumn{2}{|c|}{7} & $3 \cdot 7$ & $1 \cdot 4$ \\
\hline Newfoundland & \multicolumn{2}{|c|}{6} & $3 \cdot 2$ & $1 \cdot 3$ \\
\hline Northwest Territories & \multicolumn{2}{|c|}{1} & 0.5 & 0.5 \\
\hline Nova Scotia & \multicolumn{2}{|c|}{10} & $5 \cdot 9$ & $1 \cdot 2$ \\
\hline Nunavut & \multicolumn{2}{|c|}{2} & $1 \cdot 1$ & $0 \cdot 7$ \\
\hline Ontario & \multicolumn{2}{|c|}{51} & $27 \cdot 1$ & $3 \cdot 2$ \\
\hline Prince Edward Island & \multicolumn{2}{|c|}{4} & $2 \cdot 1$ & $1 \cdot 1$ \\
\hline Quebec & \multicolumn{2}{|c|}{45} & $23 \cdot 9$ & $3 \cdot 1$ \\
\hline Saskatchewan & \multicolumn{2}{|c|}{12} & $6 \cdot 4$ & $1 \cdot 8$ \\
\hline Yukon & \multicolumn{2}{|c|}{2} & $1 \cdot 1$ & $0 \cdot 7$ \\
\hline \multicolumn{5}{|l|}{ Classroom grade } \\
\hline 6 & \multicolumn{2}{|c|}{95} & $22 \cdot 3$ & $2 \cdot 0$ \\
\hline 7 & \multicolumn{2}{|c|}{91} & $21 \cdot 4$ & $2 \cdot 0$ \\
\hline 8 & \multicolumn{2}{|c|}{87} & $20 \cdot 4$ & $2 \cdot 0$ \\
\hline 9 & \multicolumn{2}{|c|}{81} & $19 \cdot 0$ & 1.9 \\
\hline 10 & \multicolumn{2}{|c|}{72} & $16 \cdot 9$ & $1 \cdot 8$ \\
\hline \multicolumn{5}{|l|}{ School board } \\
\hline Public schools & \multicolumn{2}{|c|}{155} & $82 \cdot 4$ & $2 \cdot 8$ \\
\hline Separate (Roman Catholic) & \multicolumn{2}{|c|}{33} & $17 \cdot 6$ & $2 \cdot 8$ \\
\hline \multicolumn{5}{|l|}{ Urban-rural status } \\
\hline Urban & \multicolumn{2}{|c|}{115} & $61 \cdot 8$ & $3 \cdot 6$ \\
\hline \multirow[t]{3}{*}{ Rural } & \multicolumn{2}{|c|}{71} & $38 \cdot 2$ & $3 \cdot 6$ \\
\hline & \multicolumn{2}{|c|}{ Within 1 km } & With & $5 \mathrm{~km}$ \\
\hline & $n$ & $\%$ & $n$ & $\%$ \\
\hline Schools with $\geq 1$ food retailer & & & & \\
\hline Full-service restaurant & 128 & $68 \cdot 1$ & 169 & $89 \cdot 9$ \\
\hline Fast-food restaurant & 59 & $31 \cdot 4$ & 130 & $69 \cdot 2$ \\
\hline Sub/sandwich shop & 53 & $28 \cdot 2$ & 125 & $66 \cdot 5$ \\
\hline Doughnut/coffee shop & 64 & $34 \cdot 0$ & 130 & $69 \cdot 2$ \\
\hline Convenience store & 109 & $58 \cdot 0$ & 150 & $79 \cdot 8$ \\
\hline Grocery store & N/A & & 143 & $76 \cdot 1$ \\
\hline
\end{tabular}


Table 3 Association between exposure to different types of food retailers within $1 \mathrm{~km}$ of schools and overweight: Canadian students participating in the 2005/06 Health Behaviour in School-aged Children Survey

\begin{tabular}{|c|c|c|c|c|c|c|}
\hline & & & \multicolumn{4}{|c|}{ Multivariate analysest } \\
\hline & \multicolumn{2}{|c|}{ Bivariate analyses } & \multicolumn{2}{|c|}{ Model 1} & \multicolumn{2}{|c|}{ Model 2} \\
\hline & OR & $95 \% \mathrm{Cl}$ & OR & $95 \% \mathrm{Cl}$ & OR & $95 \% \mathrm{Cl}$ \\
\hline Full-service restaurants & $0 \cdot 81^{* *}$ & $0.69,0.94$ & - & & - & \\
\hline Fast-food restaurants & $0 \cdot 70^{\star *}$ & $0.58,0.81$ & $0 \cdot 83^{*}$ & $0.70,0.98$ & - & \\
\hline Sub/sandwich shops & $0 \cdot 65^{\star \star}$ & $0.56,0.76$ & $0 \cdot 78^{\star \star}$ & $0.64,0.93$ & - & \\
\hline Doughnut/coffee shops & $0 \cdot 68^{\star *}$ & $0.59,0.78$ & $0 \cdot 81^{*}$ & $0.68,0.96$ & - & \\
\hline Convenience stores & $0 \cdot 79^{\star \star}$ & $0.69,0.92$ & - & & - & \\
\hline Total food retailer index & $0 \cdot 69^{\star *}$ & $0.06,0.79$ & $\mathrm{~N} / \mathrm{A}$ & & $0 \cdot 70^{\star *}$ & $0 \cdot 61,0 \cdot 81$ \\
\hline
\end{tabular}

N/A, not applicable.

Odds ratio was significant: ${ }^{\star} P<0.05,{ }^{* \star} P<0.01$.

tMultivariate models were adjusted for sex, physical activity and family affluence. The total food retailer index was considered in Model 2 but not in Model 1 . For the individual food retailers, the 'no' ( 0 retailers) exposure group served as the referent category while for the total food retailer index the group falling below the median served as the referent category.

- indicates not included in the final model.

one within $1 \mathrm{~km}$. Sub/sandwich shops were the least common, with $28.2 \%$ of the schools having at least one within $1 \mathrm{~km}$. In the bivariate analyses, each type of food retailer and the total food retailer index were negatively associated $(P<0.05)$ with overweight (Table 3$)$. In the first stepwise multivariate model (which did not consider the total food retailer index) fast-food restaurants, sub/ sandwich shops and doughnut/coffee shops were included. Youth who had access to these types of food retailers within $1 \mathrm{~km}$ of their school were less likely to be overweight compared with youth who did not have access to these types of food retailers within $1 \mathrm{~km}$ of their school (Table 3). When the total number of food retailers was considered in a second multivariate model, the individual food retailer types no longer met the inclusion criteria to be included in the model. However, the students whose schools were above the median for the total food retailer index had a reduced likelihood of being overweight compared with the students whose schools were below the median for the total food retailer index (Table 3).

\section{$5 \mathrm{~km}$ Distance - number of retailers}

Similar to the $1 \mathrm{~km}$ results, full-service restaurants were the most common and sub/sandwich shops the least common food retailer (Table 2). In the bivariate analyses, at least one of the non-referent exposure categories (low, moderate or high) for each type of food retailer and the total food retailer index were associated $(P<0.05)$ with a decreased likelihood of overweight (Table 4). When the initial multivariate model was fit for the number of food retailers at the $5 \mathrm{~km}$ distance, only full-service restaurants was included in the model (Table 4). Compared with attending schools in neighbourhoods with no full-service restaurants, participants attending schools in neighbourhoods with medium and high numbers of full-service restaurants were less likely to be overweight. When the total number of food retailers was considered in a second multivariate model, the individual food retailer types no longer met the inclusion criteria to be included in the model (Table 4).

\section{$5 \mathrm{~km}$ Distance - number of retailers per 10000} residents

In the bivariate analyses, at least one of the non-referent exposure categories (low, moderate or high) for each type of food retailer and the total food retailer index were associated $(P<0.05)$ with a decreased likelihood of overweight (Table 4). When the initial multivariate model was fit for the number of restaurants per 10000 people at the $5 \mathrm{~km}$ distance, doughnut/coffee shops and grocery stores were included in the model such that students living in neighbourhoods with a moderate exposure to these two types of food retailers were less likely to be overweight than students with no exposure. Similar observations were made in the second multivariate model that considered the total food retailer index (Table 4).

\section{Obesity outcome}

The analyses for the overweight outcome (which included both overweight and obese youth) presented in Tables 3 and 4 were re-run comparing obese with normal-weight participants. Overall the results were comparable, although there were some slight variations in the types of food retailers that were included in the multivariate models.

\section{Discussion}

The key observation of the present study is that increased exposure to food retailers, both in the immediate school environment and in the broader neighbourhood, was not associated with increased odds of overweight and obesity in Canadian school-aged youth. This relationship was consistent across all food retailer types.

Findings of the study are inconsistent with the a priori hypothesis that exposure to certain types of food retailers (fast food, doughnut/coffee shops, convenience stores) would be associated with an increased relative odds of overweight and obesity. Furthermore, the findings contradict some of the previous literature examining the 
Table 4 Association between exposure to different types of food retailers within $5 \mathrm{~km}$ of schools and overweight: Canadian students participating in the 2005/06 Health Behaviour in School-aged Children Survey

\begin{tabular}{|c|c|c|c|c|c|c|c|c|c|}
\hline \multirow[b]{2}{*}{ Food retailer type } & \multirow[b]{2}{*}{ Modelt } & \multicolumn{2}{|c|}{ None } & \multicolumn{2}{|c|}{ Low } & \multicolumn{2}{|c|}{ Medium } & \multicolumn{2}{|c|}{ High } \\
\hline & & OR & $95 \% \mathrm{Cl}$ & OR & $95 \% \mathrm{Cl}$ & OR & $95 \% \mathrm{Cl}$ & OR & $95 \% \mathrm{Cl}$ \\
\hline & & \multicolumn{8}{|c|}{ Number of food retailers within $5 \mathrm{~km}$} \\
\hline Full-service restaurant & $\begin{array}{l}\text { Bivariate } \\
\text { Multivariate } 1 \\
\text { Multivariate } 2\end{array}$ & $1 \cdot 00$ & referent & $\begin{array}{l}0 \cdot 81 \\
0 \cdot 79 \\
-\end{array}$ & $\begin{array}{l}0 \cdot 70,1 \cdot 00 \\
0.63,1 \cdot 00\end{array}$ & $\begin{array}{l}0 \cdot 74^{* *} \\
0 \cdot 74^{*} \\
-\end{array}$ & $\begin{array}{l}0.59,0.92 \\
0.58,0.93\end{array}$ & $\begin{array}{l}0.52^{\star *} \\
0.50^{\star *} \\
-\end{array}$ & $\begin{array}{l}0.42,0.66 \\
0.40,0.64\end{array}$ \\
\hline Fast-food restaurant & $\begin{array}{l}\text { Bivariate } \\
\text { Multivariate } 1 \\
\text { Multivariate } 2\end{array}$ & $1 \cdot 00$ & referent & $\begin{array}{l}0 \cdot 87 \\
- \\
-\end{array}$ & $0 \cdot 72,1 \cdot 05$ & $\begin{array}{l}0 \cdot 73^{\star \star} \\
- \\
-\end{array}$ & $0 \cdot 60,0.88$ & $\begin{array}{l}0 \cdot 70^{\star \star} \\
- \\
-\end{array}$ & $0.58,0.85$ \\
\hline Sub/sandwich shop & $\begin{array}{l}\text { Bivariate } \\
\text { Multivariate } 1 \\
\text { Multivariate } 2\end{array}$ & $1 \cdot 00$ & referent & $\begin{array}{l}0.90 \\
- \\
-\end{array}$ & $0 \cdot 75,1 \cdot 07$ & $\begin{array}{l}0 \cdot 70^{\star *} \\
- \\
-\end{array}$ & $0.57,0.85$ & $\begin{array}{l}0 \cdot 66^{\star \star} \\
- \\
-\end{array}$ & $0.55,0.79$ \\
\hline Doughnut/coffee shop & $\begin{array}{l}\text { Bivariate } \\
\text { Multivariate } 1 \\
\text { Multivariate } 2\end{array}$ & $1 \cdot 00$ & referent & $\begin{array}{l}0 \cdot 79^{*} \\
- \\
-\end{array}$ & $0.66,0.95$ & $\begin{array}{l}0 \cdot 68^{* *} \\
- \\
-\end{array}$ & $0.56,0.82$ & $\begin{array}{l}0.60^{* *} \\
- \\
-\end{array}$ & $0.50,0.72$ \\
\hline Convenience store & $\begin{array}{l}\text { Bivariate } \\
\text { Multivariate } 1 \\
\text { Multivariate } 2\end{array}$ & $1 \cdot 00$ & referent & $\begin{array}{l}0.97 \\
- \\
-\end{array}$ & $0 \cdot 80,1 \cdot 18$ & $\begin{array}{l}0 \cdot 81^{*} \\
- \\
-\end{array}$ & $0 \cdot 70,0 \cdot 98$ & $\begin{array}{l}0 \cdot 61^{\star \star} \\
- \\
-\end{array}$ & $0 \cdot 50,0 \cdot 75$ \\
\hline Grocery store & $\begin{array}{l}\text { Bivariate } \\
\text { Multivariate } 1 \\
\text { Multivariate } 2\end{array}$ & $1 \cdot 00$ & referent & $\begin{array}{l}0 \cdot 86 \\
- \\
-\end{array}$ & $0 \cdot 72,1 \cdot 02$ & $\begin{array}{l}0 \cdot 84 \\
- \\
-\end{array}$ & $0 \cdot 69,1 \cdot 01$ & $\begin{array}{l}0.55^{\star \star} \\
- \\
-\end{array}$ & $0.46,0.67$ \\
\hline Total food retailer index & $\begin{array}{l}\text { Bivariate } \\
\text { Multivariate } 1 \\
\text { Multivariate } 2\end{array}$ & $1 \cdot 00$ & referent & $\begin{array}{l}0 \cdot 84 \\
N / A \\
0 \cdot 82^{\star}\end{array}$ & $\begin{array}{l}0 \cdot 70,1 \cdot 01 \\
0.68,0.99\end{array}$ & $\begin{array}{l}0 \cdot 80^{*} \\
\mathrm{~N} / \mathrm{A} \\
0 \cdot 79^{\star}\end{array}$ & $\begin{array}{l}0.67,0.96 \\
0.66,0.95\end{array}$ & $\begin{array}{l}0.56^{* *} \\
\mathrm{~N} / \mathrm{A} \\
0.53^{\star *}\end{array}$ & $\begin{array}{l}0.47,0.68 \\
0.43,0.64\end{array}$ \\
\hline & & \multicolumn{8}{|c|}{ Number of food retailers per 10000 people within $5 \mathrm{~km}$} \\
\hline Full-service restaurant & $\begin{array}{l}\text { Bivariate } \\
\text { Multivariate } 1 \\
\text { Multivariate } 2\end{array}$ & $1 \cdot 00$ & referent & $\begin{array}{l}0 \cdot 66^{\star *} \\
- \\
-\end{array}$ & $0.51,0.85$ & $\begin{array}{l}0 \cdot 70^{\star \star} \\
- \\
-\end{array}$ & $0.55,0.90$ & $\begin{array}{l}0 \cdot 67^{\star \star} \\
- \\
-\end{array}$ & $0.52,0.86$ \\
\hline Fast-food restaurant & $\begin{array}{l}\text { Bivariate } \\
\text { Multivariate } 1 \\
\text { Multivariate } 2\end{array}$ & $1 \cdot 00$ & referent & $\begin{array}{l}0 \cdot 69^{* *} \\
- \\
-\end{array}$ & $0 \cdot 57,0 \cdot 84$ & $\begin{array}{l}0 \cdot 76^{\star *} \\
- \\
-\end{array}$ & $0.63,0.93$ & $\begin{array}{l}0.84 \\
- \\
-\end{array}$ & $0 \cdot 70,1 \cdot 01$ \\
\hline Sub/sandwich shop & $\begin{array}{l}\text { Bivariate } \\
\text { Multivariate } 1 \\
\text { Multivariate } 2\end{array}$ & $1 \cdot 00$ & referent & $\begin{array}{l}0 \cdot 69^{* *} \\
- \\
-\end{array}$ & $0 \cdot 57,0 \cdot 84$ & $\begin{array}{l}0 \cdot 77^{*} \\
- \\
-\end{array}$ & $0.64,0.94$ & $\begin{array}{l}0 \cdot 80^{*} \\
- \\
-\end{array}$ & $0.66,0.97$ \\
\hline Doughnut/coffee shop & $\begin{array}{l}\text { Bivariate } \\
\text { Multivariate } 1 \\
\text { Multivariate } 2\end{array}$ & $1 \cdot 00$ & referent & $\begin{array}{l}0 \cdot 70^{\star *} \\
0 \cdot 73^{*} \\
0 \cdot 73^{\star}\end{array}$ & $\begin{array}{l}0.58,0.85 \\
0.56,0.96 \\
0.56,0.96\end{array}$ & $\begin{array}{l}0 \cdot 64^{\star *} \\
0 \cdot 74^{\star} \\
0 \cdot 74^{\star}\end{array}$ & $\begin{array}{l}0.53,0.76 \\
0.58,0.95 \\
0.58,0.95\end{array}$ & $\begin{array}{l}0 \cdot 76^{\star \star} \\
0.85 \\
0.85\end{array}$ & $\begin{array}{l}0 \cdot 63,0 \cdot 92 \\
0 \cdot 66,1 \cdot 10 \\
0 \cdot 66,1 \cdot 10\end{array}$ \\
\hline Convenience store & $\begin{array}{l}\text { Bivariate } \\
\text { Multivariate } 1 \\
\text { Multivariate } 2\end{array}$ & $1 \cdot 00$ & referent & $\begin{array}{l}0 \cdot 86 \\
- \\
-\end{array}$ & $0 \cdot 69,1 \cdot 06$ & $\begin{array}{l}0 \cdot 76^{*} \\
- \\
-\end{array}$ & $0.62,0.93$ & $\begin{array}{l}0 \cdot 78^{*} \\
- \\
-\end{array}$ & $0.63,0.97$ \\
\hline Grocery store & $\begin{array}{l}\text { Bivariate } \\
\text { Multivariate } 1 \\
\text { Multivariate } 2\end{array}$ & $1 \cdot 00$ & referent & $\begin{array}{l}0 \cdot 82^{*} \\
1 \cdot 05 \\
1 \cdot 05\end{array}$ & $\begin{array}{l}0.68,0.99 \\
0.80,1.38 \\
0.80,1.38\end{array}$ & $\begin{array}{l}0.58^{\star *} \\
0 \cdot 70^{\star *} \\
0 \cdot 70^{\star *}\end{array}$ & $\begin{array}{l}0.49,0.70 \\
0.54,0.92 \\
0.54,0.92\end{array}$ & $\begin{array}{l}0.88 \\
0.99 \\
0.99\end{array}$ & $\begin{array}{l}0.73,1 \cdot 07 \\
0.78,1 \cdot 26 \\
0.78,1 \cdot 26\end{array}$ \\
\hline Total food retailer index & $\begin{array}{l}\text { Bivariate } \\
\text { Multivariate } 1 \\
\text { Multivariate } 2\end{array}$ & $1 \cdot 00$ & referent & $\begin{array}{l}0 \cdot 68^{* *} \\
N / A \\
-\end{array}$ & $0 \cdot 56,0.83$ & $\begin{array}{l}0 \cdot 73^{\star *} \\
N / A \\
-\end{array}$ & $0 \cdot 60,0.89$ & $\begin{array}{l}0 \cdot 79^{*} \\
\mathrm{~N} / \mathrm{A} \\
-\end{array}$ & $0.65,0.96$ \\
\hline
\end{tabular}

N/A, not applicable.

Odds ratio was significant: ${ }^{\star} P<0 \cdot 05,{ }^{\star \star} P<0 \cdot 01$.

tMultivariate models were adjusted for sex, physical activity and family affluence. The total food retailer index was considered in Model 2 but not in Model 1 . For the individual food retailers, the 'no' (0 retailers) exposure group served as the referent category while for the total food retailer index the lowest quartile served as the referent category.

- indicates not included in the final model.

relationship between measures of adiposity and food retailers. A study by Maddock ${ }^{(4)}$ found that a high density of fast-food restaurants was associated with a higher prevalence of obesity throughout the USA, while our study found the opposite. Morland et al. ${ }^{(5)}$ found that grocery stores and convenience stores were associated with a higher prevalence of adult obesity, while supermarkets were associated with a lower prevalence of adult obesity. Conversely, Wang et al. ${ }^{(26)}$ reported that a higher density of grocery stores and closer proximity to super- markets were both associated with a higher BMI, but in women only. Notable SES gradients in exposure to food retailers in the American setting may be a reflection of the larger income disparities found in comparison to Canada $^{(28,29)}$. Additionally, there may be different proportions of chain and non-chain food retailers in Canada and the USA which may account for these differences.

Although our findings are dissimilar to most existing analogous research, they were consistent across distance, whether food retailers were considered together or 
separately, and also after taking population density into account. We speculate that having access to a variety of food retailers may be beneficial, at least within the Canadian context, because this increased access provides the individual with a broad variety of choices rather than forcing them to rely on a limited selection of options. It may not be the type of food retailer that is important per se, but the opportunity to select healthier choices that may explain our results. However, further research is needed to determine the mechanism behind this relationship.

It is possible that in our study the number of food retailers may have captured the effect of more complex features of the school and surrounding environment. Other aspects of the environment such as the availability of recreational facilities ${ }^{(30,31)}$ and nearby parks ${ }^{(30,32)}$ are associated with the frequency of physical activity and BMI in youth. It is plausible that the presence of food retailers is positively correlated with the presence of facilities that promote physical activity, which could explain the lower levels of overweight and obesity in schools that are close to various food retailers. The use of objective measures such as the $1 \mathrm{~km}$ and $5 \mathrm{~km}$ radii around schools may have good face value in describing the food environment, but it is less clear if objective measures accurately capture the impact of built environment on obesity. Recent studies have revealed that there are inconsistencies between how objective and perceived measures of the built environment relate to physical activity ${ }^{(33,34)}$, although it is not known if the same is true for eating behaviours and obesity. It is likely that other unknown factors determine whether students choose to purchase food available to them. For example, the distinction between chain and non-chain restaurants may be important to youth, who may be more likely to purchase foods marketed by large chain retailers. Also, over time people may become accustomed to the food retailers within their environment and become less likely to frequent them. Due to the largely close-ended nature of the HBSC survey, we were unable to explore this hypothesis. The relationship between the objectively measured food environment, perceived environment and obesity has yet to be fully developed.

The present study has several limitations. First, we were unable to take into account internal sources of food within the schools, such as vending machines and cafeterias. These food sources may have been particularly important for rural schools, which have less access to external food retailers, and urban schools with policies on leaving school grounds during the school day. Future studies investigating the food environment around schools should include information on the availability and quality of internal food sources such as cafeterias and vending machines, and whether students consume foods brought from home. Furthermore, the HBSC survey did not include information on whether school policy allowed students to leave school property during breaks. With this information, the relationship between school food environment and obesity may become clearer. Second, because the students' home addresses were not collected in the survey, the $5 \mathrm{~km}$ radius surrounding each school was used as a proxy for the neighbourhoods of the students attending that school. Some students lived outside this area, and the access to the food environment within $5 \mathrm{~km}$ of their home may have differed from that of their school. Third, we cannot make the assumption that the presence of food retailers was associated with the consumption of the foods they sold. Conclusions can only be made about the availability of the food retailers and measures of adiposity, rather than individual-level behaviours that may also be associated with negative health outcomes. Fourth, we only considered half of the energy balance equation. Environmental factors influencing physical activity levels were not considered in the study. Finally, because the heights and weights used to calculate BMI status were obtained through self-report, there was likely some non-differential misclassification bias that could have decreased the magnitude of the relationship between overweight/obesity and food retailers.

The results of our study revealed that the effect of the environment on overweight and obesity is complex. It appears that the effect of food environment on overweight and obesity in Canadian youth is notably different from what has been found in American studies. According to our results, policy interventions limiting the number and type of food retailers within the school environment may not be an effective strategy for the prevention and reduction of overweight and obesity in youth. Future research is needed to provide a greater understanding of the mechanisms behind this relationship as well as other environmental determinants of overweight and obesity in adolescents.

\section{Acknowledgements}

The submission represents original work that has not been published previously, is not currently being considered by another journal, and that following acceptance for Public Health Nutrition will not be published elsewhere in the same form, in English or in any other language. Each author has seen and approved the contents of the submitted manuscript. None of the authors has any conflicts of interest to declare. All of the authors have contributed substantially to the manuscript. Specifically, L.M.S., I.J. and W.P. contributed to the study conception and design. All authors contributed substantially to the interpretation of the results and data analyses. L.M.S. wrote the draft of the manuscript while I.J., W.P. and W.F.B. revised it for important intellectual content. The study was supported by research agreements with the Canadian Institutes of Health Research (operating grant: 2004MEP-CHI-128223-C) and the Public Health Agency of Canada (contract: HT089-05205/001/SS) which funds the Canadian version of the WHO Health Behaviour in School-aged Children survey (WHO-HBSC). 
The WHO-HBSC is a WHO/Euro collaborative study. International Coordinator of the 2005-2006 study: Candace Currie, University of Edinburgh, Scotland; Data Bank Manager: Oddrun Samdal, University of Bergen, Norway. This publication reports data solely from Canada (Principal Investigator: W.F.B.). The authors would like to thank the researchers and participants involved in the HBSC survey. L.M.S. was partially supported by a fellowship from the Empire Life Insurance company. I.J. was supported by a New Investigator Award from the Canadian Institutes of Health Research and an Early Researcher Award from the Ontario Ministry of Research and Innovation.

\section{References}

1. Shields M (2006) Overweight and obesity among children and youth. Health Rep 17, 27-42.

2. Summerbell CD, Ashton V, Campbell KJ, Edmunds L, Kelly S \& Waters E (2003) Interventions for treating obesity in children. Cochrane Database Syst Rev issue 3, CD001872.

3. Cummins S \& Macintyre S (2006) Food environments and obesity - neighbourhood or nation? Int J Epidemiol 35 100-104.

4. Maddock J (2004) The relationship between obesity and the prevalence of fast food restaurants: state-level analysis. Am J Health Promot 19, 137-143.

5. Morland K, Diez Roux AV \& Wing S (2006) Supermarkets, other food stores, and obesity: the Atherosclerosis Risk in Communities Study. Am J Prev Med 30, 333-339.

6. Burdette HL \& Whitaker RC (2004) Neighborhood playgrounds, fast food restaurants, and crime: relationships to overweight in low-income preschool children. Prev Med 38, 57-63.

7. Sturm R \& Datar A (2005) Body mass index in elementary school children, metropolitan area food prices and food outlet density. Public Health 119, 1059-1068.

8. Austin SB, Melly SJ, Sanchez BN, Patel A, Buka S \& Gortmaker SL (2005) Clustering of fast-food restaurants around schools: a novel application of spatial statistics to the study of food environments. Am J Public Health 95, 1575-1581.

9. Roberts C, Currie C, Samdal O, Currie D, Smith R \& Maes L (2007) Measuring the health and health behaviours of adolescents through cross-national survey research: recent developments in the Health Behaviour in School-aged Children (HBSC) study. J Public Health 15, 179-186.

10. Statistics Canada (2003) Enrolment in Elementary and Secondary Schools. Catalogue no. 81-229-XIB. Ottawa: Statistics Canada.

11. Apparicio P, Cloutier MS \& Shearmur R (2007) The case of Montreal's missing food deserts: evaluation of accessibility to food supermarkets. Int J Health Geogr 6, 4 .

12. Simpson K, Janssen I, Craig WM \& Pickett W (2005) Multilevel analysis of associations between socioeconomic status and injury among Canadian adolescents. J Epidemiol Community Health 59, 1072-1077.

13. Moore LV \& Diez Roux AV (2006) Associations of neighborhood characteristics with the location and type of food stores. Am J Public Health 96, 325-331.

14. Reidpath DD, Burns C, Garrard J, Mahoney M \& Townsend M (2002) An ecological study of the relationship between social and environmental determinants of obesity. Health Place 8, 141-145.

15. Cummins SC, McKay L \& MacIntyre S (2005) McDonald's restaurants and neighborhood deprivation in Scotland and England. Am J Prev Med 29, 308-310.
16. Oliver LN \& Hayes MV (2005) Neighbourhood socioeconomic status and the prevalence of overweight Canadian children and youth. Can J Public Health 96, 415-420.

17. Veugelers PJ \& Fitzgerald AL (2005) Prevalence of and risk factors for childhood overweight and obesity. CMAJ 173, 607-613.

18. Janssen I, Boyce WF, Simpson K \& Pickett W (2006) Influence of individual- and area-level measures of socioeconomic status on obesity, unhealthy eating, and physical inactivity in Canadian adolescents. Am J Clin Nutr 83, 139-145.

19. Statistics Canada (2001) 2001 Census Dictionary. Catalogue no. 92-378-XIE02002. Ottawa: Statistics Canada.

20. Cole TJ, Bellizzi MC, Flegal KM \& Dietz WH (2000) Establishing a standard definition for child overweight and obesity worldwide: international survey. BMJ320, 1240-1243.

21. Parsons TJ, Power C, Logan S \& Summerbell CD (1999) Childhood predictors of adult obesity: a systematic review. Int J Obes Relat Metab Disord 23, Suppl. 8, S1-S107.

22. Currie C, Samdal O, Boyce WF \& Smith B (2001) Health Behaviour in School-Aged Children: a World Health Organization Cross-National Study. Research Protocol for the 2001/02 Survey. Edinburgh: Child and Adolescent Health Research Unit, University of Edinburgh; available at http://www.hbsc.org/overview_studydesign.html

23. Veugelers PJ, Yip AM \& Kephart G (2001) Proximate and contextual socioeconomic determinants of mortality: multilevel approaches in a setting with universal health care coverage. Am J Epidemiol 154, 725-732.

24. Block JP, Scribner RA \& DeSalvo KB (2004) Fast food, race/ ethnicity, and income: a geographic analysis. Am J Prev Med 27, 211-217.

25. Morland K, Wing S, Diez Roux A \& Poole C (2002) Neighborhood characteristics associated with the location of food stores and food service places. Am J Prev Med 22, 23-29.

26. Wang MC, Kim S, Gonzalez AA, MacLeod KE \& Winkleby MA (2007) Socioeconomic and food-related physical characteristics of the neighbourhood environment are associated with body mass index. J Epidemiol Community Health 61, 491-498.

27. Diez-Roux AV (2000) Multilevel analysis in public health research. Annu Rev Public Health 21, 171-192.

28. Ross NA, Dorling D, Dunn JR, Henriksson G, Glover J, Lynch J \& Weitoft GR (2005) Metropolitan income inequality and working-age mortality: a cross-sectional analysis using comparable data from five countries. J Urban Health 82, 101-110.

29. Ross NA, Wolfson MC, Dunn JR, Berthelot JM, Kaplan GA \& Lynch JW (2000) Relation between income inequality and mortality in Canada and in the United States: cross sectional assessment using census data and vital statistics. BMJ 320, 898-902.

30. Norman GJ, Nutter SK, Ryan S, Sallis JF, Calfas KJ \& Patrick K (2006) Community design and access to recreational facilities as correlates to adolescent physical activity and body mass index. J Phys Act Health 3, S118-S128.

31. Gordon-Larsen P, Nelson MC, Page P \& Popkin BM (2006) Inequality in the built environment underlies key health disparities in physical activity and obesity. Pediatrics 117, 417-424.

32. Cohen DA, Ashwood JS, Scott MM, Overton A, Evenson KR, Staten LK, Porter D, McKenzie TL \& Catellier D (2006) Public parks and physical activity among adolescent girls. Pediatrics 118, e1381-1389.

33. Boehmer TK, Hoehner CM, Deshpande AD, Brennan Ramirez LK \& Brownson RC (2007) Perceived and observed neighborhood indicators of obesity among urban adults. Int J Obes (Lond) 31, 968-977.

34. McGinn AP, Evenson KR, Herring AH, Huston SL \& Rodriguez DA (2007) Exploring associations between physical activity and perceived and objective measures of the built environment. J Urban Health 84, 162-184. 